\title{
Isotope effects of radiation on fossil organic matter
}

\author{
MARIA NAUMENKO-DÈZES ${ }^{1}$, WOLFRAM KLOPPMANN ${ }^{1}$, \\ MICHAELA BLESSING ${ }^{1}$, RAPHAËL BONDU ${ }^{1}$, ERIC \\ GAUCHER $^{2}$, AVNER VENGOSH ${ }^{3}$ \\ ${ }^{1}$ BRGM, 3 Avenue Claude Guillemin, 45100 Orléans, France. \\ m.dezes@brgm.fr \\ ${ }^{2}$ TOTAL, CSTJF, Avenue Larribau, 64018 Pau, France \\ ${ }^{3}$ Nicholas School of the Environment, Box 90227, Duke \\ University Durham, North Carolina 27708, United States.
}

The Alum Shale formation (Mid-Cambrian to Tremadoc, Northern Europe) is a prominent example of uranium-rich black shales, where the contents of U [1] vary with age (highest averages of 100-300 ppm in the U-Cambrian), laterally, and in function of TOC (up to $8000 \mathrm{ppm}$ in discrete TOC-rich nodules or layers). Considering that they were formed $\sim 500 \mathrm{Ma}$ ago, the radiation dose obtained by the organic matter is significant, which causes changes in its structure and properties, such as increase of aromaticity, condensation degree, vitrinite reflectance and, to some extent, isotopic signatures. These changes are explained by radiationinitiated cross-linking of organic molecules that results in aromatization and polymerization in the kerogens [2] [3] [4]. The Alum Shale kerogen, of algal or planktonic origin (type I or II), sometimes shows pseudo-type III geochemical signatures [5] [6] in spite of the fact that higher land plants did not exist in the Lower Palaeozoic. This effect could be caused by the radiation-induced aromatization and polymerization of the organic matter leading to the occurrence of more complex organic molecules that are also more prone to gas generation. Indeed, increased $U$ content of the shales leads to increased gas production compared to other marine shales (e.g. [7]).

Direct impact of the radiation-induced structural changes on the $\mathrm{C}$-isotopic signatures of organic matter has been shown to be low (e.g. [7]). However, we postulate that isotopic signatures of the maturation products (gas, oil) from the structurally altered kerogen, could differ from unaltered ones.

[1] Schovsbo (2002) Gff, 2002. 124(2): p. 107-115. [2] Lewan\&Buchard (1989) Geochim\&Cosmochim.Acta. 53, pp1307-1322. [3] Court et al. (2006) Geochim\&Cosmochim.Acta. 70(4), pp. 1020-1039. [4] Yang et al. (2019) Int. J. of Coal Geology. 209, pp. 89-93. [5] Zhang et al. (2020) J of Env. Radioactivity. 211, pp. 106-105. [6] Lecomte et al. (2017) Ore Geology Reviews. 88, pp. 7198. [7] Yang et al. (2018) Geochim\&Cosmochim.Acta. 229: pp. 20-35. 